\title{
Performance assessment of the database downscaled ocean waves (DOW) on Santa Catarina coast, South Brazil
}

\author{
PAULA G. SILVA ${ }^{1}$, ANTONIO H.F. KLEIN ${ }^{1}$, MAURICIO GONZÁLEZ ${ }^{2}$, \\ OMAR GUTIERREZ ${ }^{2}$ and ANTONIO ESPEJO ${ }^{2}$ \\ ${ }^{1}$ Programa de Pós-Graduação em Geografia, Universidade Federal de Santa Catarina (UFSC), Laboratório de \\ Oceanografia Costeira, Servidão dos Coroas, Fundos s/n, Barra da Lagoa, 88040-900 Florianópolis, SC, Brasil \\ ${ }^{2}$ Environmental Hydraulics Institute "IH-Cantabria", Universidad de Cantabria, \\ Calle Isabel Torres N. 15. Santander, Postal Code 39011, Spain
}

Manuscript received on June 30, 2014; accepted for publication on November 7, 2014

\begin{abstract}
This work presents a validation of wave parameters from the new sixty years Downscaled Ocean Waves (DOW) reanalysis database. This study compares quantiles of the Gumbel distribution of Hs (significant wave height) and $\mathrm{Tp}$ (peak period) from simulated data with an 11 months' time series obtained from a buoy moored seaward on the Santa Catarina coast. Analysis by means of Gumbel distribution quantiles allows more weight to be given to the highest values of the time series, which are especially important in design projects. The statistical parameters used to verify the fit between the measured and the modeled data included: RMSE, BIAS, Scatter Index and Pearson Correlation Coefficient. Mean direction $(\theta \mathrm{m})$ validation was conducted qualitatively. The database showed good fit of the mean conditions, especially Hs which was well reproduced by the wave model. Underestimation of Tp, related mainly to the low spatial and temporal resolution of wind data used to generate waves, highlights this general modeling problem. Based on calculated statistical parameters, DOW data were considered comparable to the values obtained by measurements; however, such data must be cautiously used for extreme events analysis and in areas of bimodal sea conditions, where major deficiencies in the database were observed.
\end{abstract}

Key words: DOW, validation, wave reanalysis, WAVEWATCHIII.

\section{INTRODUCTION}

Understanding free surface oscillations of the ocean is essential for establishing safety guidelines for coastal projects and navigation. Wave data are indispensable in establishing coastal engineering projects, coastal vulnerability analysis and risk, as well as safety references for vassels traveling near the coast (Reguero et al. 2012). Over the past

Correspondence to: Paula Gomes da Silva

E-mail: silvapgomes@gmail.com few decades there has been an increasing interest in wave data collection from buoys and satellite altimeters. Buoys provide accurate variations of the free surface; however, these buoys usually collect data for short periods, and do not represent the spatial variation. On the other hand, data from satellite altimetry represent the spatial variation of wave height values, but have limited temporal resolution, since the data are collected only when the satellite passes over the point of interest. These 
problems have motivated the use of reanalysis data generated by numerical models. Through numerical modeling of wave generation, it is possible to obtain data on homogeneous temporal and spatial scales. In addition, if properly calibrated, the models allow a detailed description of extreme wave regime in areas where long-term records of buoys are not available.

Third generation models are state of the art on numerical modeling of waves (Young 1999). The most relevant and widely used of those models are WAM (Hasselman et al. 1988) and WAVEWATCHIII - WW3 (Tolman 1991) for oceanic modeling, and SWAN (Booij et al. 1999) on coastal modeling (Heras et al. 1995, Brown 2010, Mostafa Siadatmousavi et al. 2011, Reguero et al. 2012, Arinaga and Cheung 2012, Camus et al. 2013, Chawla et al. 2013, Rascle 2013). In recent decades, many studies have been carried out in order to generate wave data from atmospheric reanalysis and validate this time series. Sterl and Caires (2005) used the WAM model to generate a global wave reanalysis aiming to validate data from project ERA atmospheric reanalysis with 15 years of available data (1979-1993, ERA-15). However, underestimation was observed in areas with the highest significant wave height (Hs) values and overestimation in areas with low Hs values. Later, the database was expanded to a 40-year reanalysis data (ERA-40), including atmospheric and wave data assimilation in a $1.5^{\circ}$ resolution grid (Uppala et al. 2005). When compared with data measured from buoys, the underestimation of higher values of Hs and overestimation of minor values remained (Sterl and Caires 2005). The database was then corrected (C-ERA-40) (Caires and Sterl 2005a) through a nonparametric method (Caires and Sterl 2005b). Although an improvement was observed, some underestimations in the largest quantiles of Hs still remained.

Well known and used in many studies, the reanalysis provided by NOAA (National Oceanic and Atmospheric Administration) uses the WW3 model to generate waves in global scale. The latest version of the model (NWW3 - NOAA WAVEWATCHIII) is performed in a $0.5^{\circ}$ resolution grid using data from atmospheric reanalysis from the Climate Forecast System Reanalysis and Reforcast (CFSRR / NCEP) for the period ranging from 1979 to 2009 (Saha et al. 2010). In general, the database showed good fit to the measured wave climate, especially in offshore areas. Nevertheless, there is some overestimation of CFSRR wind data for the period before 1994 in the southern hemisphere, which results in Hs overestimation in this area (Chawla et al. 2013). Furthermore, the wind reanalysis database used only reproduces some of the extreme events, resulting in underestimation of larger waves (underestimation of peak period -Tp) (Chawla et al. 2013). D.F. Aguiar et al. (unpublished data) compared Hs and Tp from NWW3 model and measured data collected from a buoy moored in the coast of Rio Grande do Sul. Based on the calculated statistical parameters used for the comparison, the model showed a good performance in simulating waves around that coast. Nevertheless, the results also indicated a tendency for underestimation of higher values of $\mathrm{Hs}$ and $\mathrm{Tp}$, which represents extreme events.

Reguero et al. (2012) used atmospheric data from NCEP Reanalysis 1 (with $1.9^{\circ}$ of spatial resolution and 6 hours of temporal resolution) for generating a 60 years global wave database (1948 - 2008) called Global Ocean Waves (GOW). The simulations were performed using the WW3 in a global grid with $1.5^{\circ} \times 1^{\circ}$ spatial resolution and nesting grids with higher detail along Latin American and the Caribbean coasts. On the Brazilian coast, the detailed grid presents $0.5^{\circ}$ resolution. The $\mathrm{Hs}$ values were calibrated according to the direction of each sea state, following the calibration method proposed by Mínguez et al. (2011). This method consists in using buoy and satellite data to correct Hs results based on a nonlinear regression problem. 
The correction parameters vary smoothly along the possible wave directions by means of cubic splines This allows different correction, according to the wave direction of the sea state (Mínguez et al. 2011). The results of Hs and Tp from GOW database were then validated by comparing reanalysis and measured data (buoys and altimeters). An analysis by pars (data-data) would consider mainly the central portion of the distribution where most data are located. In order to give more weight to the highest values, which are specially important from the design point of view, the authors used quantiles of the Gumbel distribution to compare measured and simulated data. The results of the validation showed a slight overestimation of $\mathrm{Hs}$ values. Correlation associated with $\mathrm{Tp}$ was lower than that associated with Hs.

Later, studies within the project "Support for the Brazilian Coast Management" (SMC Brazil), detected the need for a wave database for the entire Brazilian coast with high spatial and temporal resolution. That database, called DOW (Downscaled Ocean Waves), was then generated through a downscaling of GOW data all the way to coastal waters using the SWAN model (Camus et al. 2013). Unlike the reanalysis presented above, DOW data were generated especifically to represent wave climate along the Brazilian coast. The results are available in the SMC Brazil database for use in coastal enviromental and engineering projects. Still, validation analysis are required, because only few measured data are available over the coast.

This work validates $\mathrm{Hs}, \mathrm{Tp}$ and mean direction $(\theta \mathrm{m})$ from DOW reanalysis, based on an 11 month time series obtained from a Waverider buoy moored $35 \mathrm{Km}$ seaward from the Santa Catarina coast. The methodology proposed by Reguero et al. (2012) was applied and the Gumbel quantiles from measured and simulated data were compared. Quantitative directional validation implies in more complex analysis, so $\theta \mathrm{m}$ data were compared qualitatively.

\section{MATERIALS AND METHODS}

REANALYSIS DATA (DOW - SMC BRAZIL)

The DOW database consists of a 60 years' hourly time series of $\mathrm{Hs}$; mean period (Tm); Tp; $\theta \mathrm{m}$; peak direction $(\theta p)$; directional spread; and energy spectrum from 1948 to 2008 . Wave data with very high spatial resolution ( $1 \mathrm{Km}$ from 0 to $20 \mathrm{~m}$ depth and $10 \mathrm{Km}$ from $20 \mathrm{~m}$ depth on) is available for all Brazilian coasts $(\sim 7000 \mathrm{Km})$.

The database was generated in two main steps: i) first, a global reanalysis was performed by means of generating and propagating wave spectra through parameters such as Hs, Tp and $\theta \mathrm{m}$. Global winds (Reanalysis 1 - NCEP/NCAR), ice (NCEP/ NCAR) and bathymetry (GEBCO) data were used as input for the WW3 model, which resulted in wave parameters for all oceans around the globe (Reguero et al. 2012); ii) second, focusing on the generation of regional data with higher resolution, a downscaling was conducted by propagating GOW parameters to shallow waters in 17 grids along the Brazilian coast using coastal bathymetry and winds (Reanalysis 1 - NCEP/NCAR) on SWAN model (Camus et al. 2013). Details of all steps for GOW and DOW generation can be found in Reguero et al. (2012) and Camus et al. (2013).

The wind reanalysis used to generate the GOW and DOW database was the NCEP/NCAR Reanalysis 1. This reanalysis is based on wind fields with spatial resolution of $1.9^{\circ}$ and temporal resolution of 6 hours for a period of 60 years (1948-2008). This reanalysis was chosen to provide longer wave time series (Reguero et al. 2012). Since satellite wind measurements are available only from 1978 (Kistler et al. 2001), wind data assimilation were possible only after that time, and the wind reanalysis is more reliable for the past 40 years. However, the calibration method used on GOW reanalysis proved to be a good adjustment for the wave data resulting from these winds (Reguero et al. 2012). 
DOW data available for the coast of Santa Catarina are shown in Figure 1. Because D1 $\left(27^{\circ} 42^{\prime} 55^{\prime \prime} \mathrm{S}, 48^{\circ} 10^{\prime} 50.16^{\prime \prime} \mathrm{O}\right)$ and $\mathrm{D} 2\left(27^{\circ} 42^{\prime} 55^{\prime \prime} \mathrm{S}\right.$, $\left.48^{\circ} 4^{\prime} 46.2^{\prime \prime} \mathrm{O}\right)$ DOW points lie closer to the Waverider buoy (WR), they were used in the validation process.
No interpolation techniques were applied to verify the data over the exact WR point, since comparison between data from D1 and D2 has shown similar values (maximum difference obtained was $0.2 \mathrm{~m}$ for Hs and 1.49 s for $\mathrm{Tp}$ ).

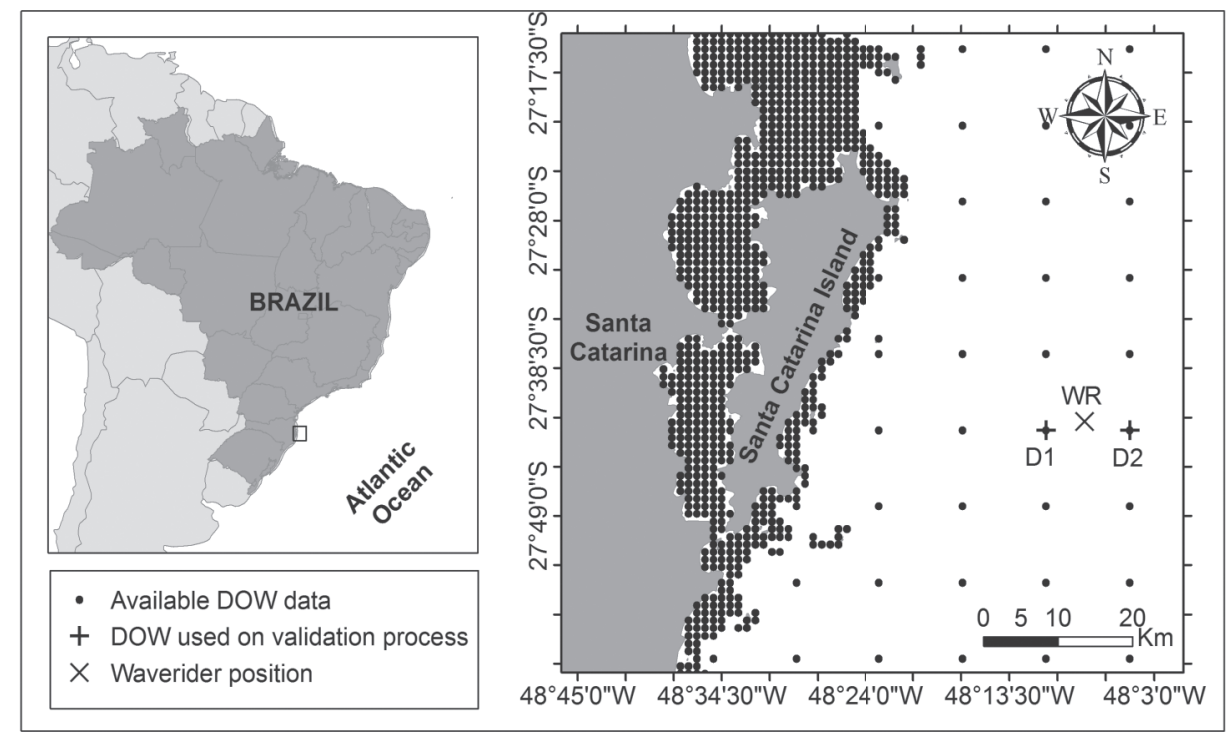

Figure 1 - Study area with D1, D2 and WR location. Black dots represents all DOW points available in this area.

\section{MEASUREMENT DATA (WAVERIDER BUOY)}

Directional wind-wave spectra were measured by the Coastal Information Program (Programa de Informação Costeira - PIC) developed at the Marine Hydraulics Laboratory (Laboratório de Hidráulica Marítima - LaHiMar), of the Federal University of Santa Catarina (UFSC). The equipment was a Waverider Datawell II buoy moored at $80 \mathrm{~m}$ depth, $35 \mathrm{Km}$ seaward from the Santa Catarina Island

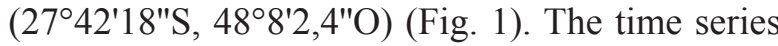
covers 11 months from 2004 to 2005 (MAY/04, JUN/04, JUL/04, OCT/04, NOV/04, DEC/04, JAN/05, FEB/05, MAR/05, APR/05 and MAY/05) with $\mathrm{N}=5435$. This data is part of a larger time series ( 5 years series) published previously by Araujo et al. (2003), Melo F ${ }^{o}$ et al. (2006), Franco and Melo $F^{\circ}$ (2008). This 11 months' series is available on the internet at www.ndbc.noaa.gov and cdip.ucsd.edu.

\section{VALIDATION METHODOLOGY}

The methodology employed in this work consists of comparing data from DOW reanalysis (points D1 and D2) and data from the WR buoy by quantiles of the Gumbel distribution. An initial analysis of the three time series was undertaken by a data-data assessment, comparing mean, mode and standard deviation. Then, methodology used by Reguero et al. (2012) was applied to quantify the quality of the fit between reanalysis and measured data. After fitting the three time series to the Gumbel distribution, the quantiles were estimated. With these values, different statistic parameters were calculated to validate the reanalysis.

This methodology is applicable to $\mathrm{Hs}$ and $\mathrm{Tp}$, but cannot be applied to mean wave direction. Directional validation requires more complex analysis and so there are only a few studies that assess the quality of directional results from reanalysis. 
Nevertheless, a primary qualitative analysis of $\theta \mathrm{m}$ was carried out in this study and will also be shown.

\section{Gumbel distribution}

In wave analysis, symmetric probability distribution functions, such as the normal distribution, are not suitable to describe the long term Hs data (Battjes 1972). In these cases, skewed distributions such as Gumbel can show a better fit. Beside this, as mentioned above, by using Gumbel quantiles on the validation process it is possible to give more weight to the maximum values of the distribution (Mínguez et al. 2011, Reguero et al. 2012). The cumulative probability of the Gumbel distribution was used in this work and was given by:

$$
\begin{gathered}
\operatorname{Pr}=\exp \left[-\exp \left(-\frac{x-A}{B}\right)\right] \\
Q(\operatorname{Pr})=A-B * \operatorname{In}(1-\operatorname{Pr})
\end{gathered}
$$

Where $\operatorname{Pr}$ is the cumulative probability of an event $x, A$ is the location parameter, $B$ is the scale parameter (determines the width of the distribution) and $Q(P r)$ is the quantil of the distribution. $A$ represents the mode value of the time series and $B$ is proportional to the standard deviation $(\sigma)$ of the distribution: $\sigma^{2}=\pi^{2} B^{2} / 6$. The values for $A$ and $B$ calculated in this work are represented on Table I.

\section{TABLE I}

Values for $A$ and $B$ parameters used to calculate the quantiles of the Gumbel distributions for the three time series.

\begin{tabular}{ccccc}
\hline Time & \multicolumn{2}{c}{ Hs } & \multicolumn{2}{c}{ Tp } \\
\cline { 2 - 5 } Series & $\mathbf{A}$ & $\mathbf{B}$ & $\mathbf{A}$ & $\mathbf{B}$ \\
\hline D1 & 1.522 & 0.4395 & 7.191 & 1.356 \\
D2 & 1.555 & 0.4791 & 7.286 & 1.43 \\
WR & 1.463 & 0.4749 & 7.984 & 1.833 \\
\hline
\end{tabular}

\section{Statistical parameters}

In order to access the quality of the numerical simulated results from reanalysis ( $y$ ), these were compared to instrumental data $(x)$ by calculating statistical parameters obtained from the literature (Janssen 1997, Melo $\mathrm{F}^{\text {o }}$ et al. 2008, 2010, D.F.
Aguiar et al., unpublished data, Reguero et al. 2012, Chawla et al. 2013). The parameters used in this work are described below:

Root Mean Square Error (RMSE) - Measures the difference between an estimated value and the true value.

$$
R M S=\sqrt{\frac{1}{N} \sum_{i=1}^{N}\left(x_{i}-y_{i}\right)^{2}}
$$

$\boldsymbol{B I A S}$ - Deviation between two variables. BIAS can be defined as the difference between the averages of the time series.

$$
B I A S=\bar{x}-\bar{y}
$$

Scatter Index (SI) - Dimensionless parameter which measures dispersion with regard to the line $\mathrm{x}=\mathrm{y}$ (ideal):

$$
S I=\frac{R M S E}{\bar{x}}
$$

Pearson Correlation Coefficient ( $\rho$ ) - Measures the intensity of the relation between two variables, with values ranging from 0 (no correlation) to 1 (perfect correlation).

where $\mathrm{R}^{2}$ is:

$$
\rho=\sqrt{R^{2}}
$$

$$
R^{2}=\frac{\sum_{i=1}^{N}\left(x_{i}-\bar{y}\right)^{2}}{\sum_{i=1}^{N}\left(y_{i}-x_{i}\right)^{2}+\left(x_{i}-\bar{y}_{i}\right)^{2}}
$$

Symmetric Slope (SS) - Also known as the regression slope. On an ideal situation, $\mathrm{SS}=1$. Values of SS bigger than 1 indicate overestimation of high values or underestimation of low values. The opposite occurs if SS $<1$.

$$
T=\sqrt{\frac{\sum_{i=1}^{N} y_{i}^{2}}{\sum_{i=1}^{N} x_{i}^{2}}}
$$

\section{RESULTS AND DISCUSSION}

\section{Wave Height AND PEAK Period}

To illustrate the comparison between the measured and the simulated data, Figure 2 shows Hs, Tp and $\theta \mathrm{m}$ values from D2 and WR series. On an initial 
qualitative analysis, a similar behavior between Hs values from reanalysis and WR data was observed, even though overestimation can be seen in some peaks (e.g. July/2004 and from March to
May/2005). For Tp values, despite showing similar trends on high and low peaks, underestimation of simulated data can be observed in almost the entire series.

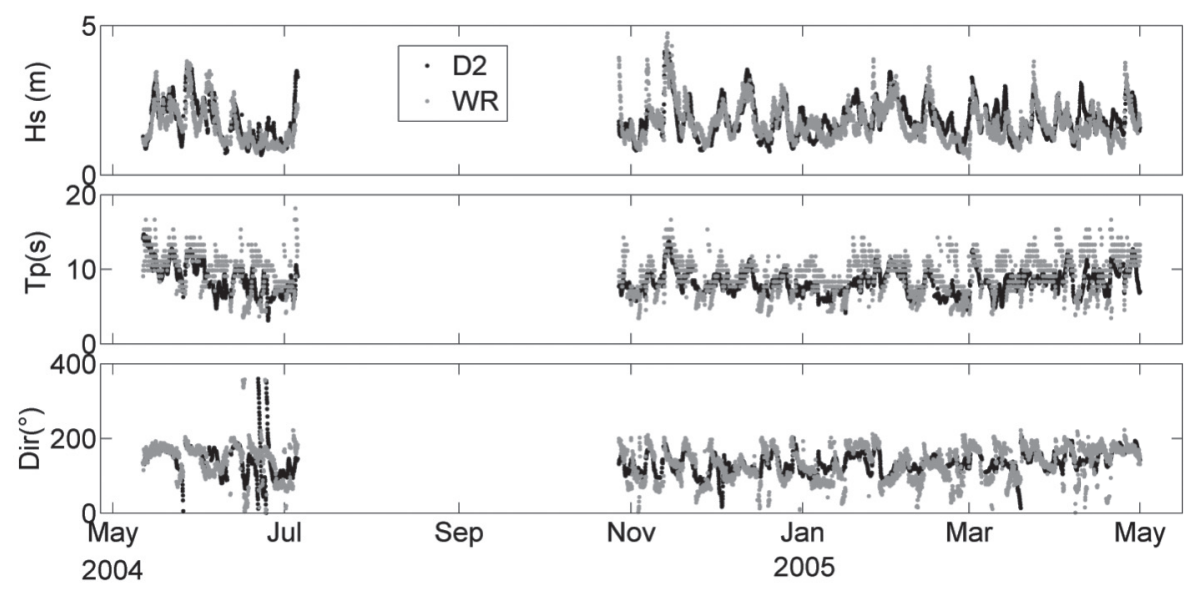

Figure 2 - D2 (black) and WR (gray) time series from JAN/05 to APR/2005. D1 is very similar to $\mathrm{D} 2$, and so it is not represented.

The basic descriptive statistic parameters (mean, standard deviation and mode) for $\mathrm{Hs}$ and Tp of the three time series are shown on Table II. The values show agreement between the simulated and the observed statistic parameters. The main differences can be seen in the Tp mean, with higher values in observed data, and in Hs mode. The Hs mode shows most sea states over $1.73 \mathrm{~m}$ and $1.79 \mathrm{~m}$ in $\mathrm{D} 1$ and $\mathrm{D} 2$ respectively, about $0.5 \mathrm{~m}$ higher than what occurs in WR.

Figure 3 shows the density dispersion between the entire series of measured and simulated data. The overestimation of the Hs mode is explicit, with most estimated sea states occurring approximately $0.5 \mathrm{~m}$ above measured data, even though the Hs dispersion

TABLE II

Basic descriptive statistical parameters for the three time series.

\begin{tabular}{ccccccccccc}
\hline & \multicolumn{3}{c}{ D1 } & \multicolumn{4}{c}{ D2 } & \multicolumn{3}{c}{ WR } \\
\cline { 2 - 10 } & Mean & Std & Md & Mean & Std & Md & Mean & Std & Md \\
\hline Hs (m) & 1.79 & 0.61 & 1.73 & 1.84 & 0.64 & 1.79 & 1.73 & 0.62 & 1.29 \\
Tp (s) & 8.35 & 1.75 & 8.07 & 8.38 & 1.8 & 7.48 & 9.44 & 2.41 & 7.50 \\
\hline
\end{tabular}

shows that most of the sea states from reanalysis are near the ideal fit (dashed line), with a few cases of high dispersion. The Tp dispersion also shows the majority of the cases occurring near what would be considered ideal, nevertheless an underestimation of the higher values can be observed.

The dispersion between the simulated and the measured quantiles is shown in Figure 4. As can be seen in this figure, Hs data are well represented by the reanalysis, especially when comparing WR with D1, although a slight overestimation of the greatest values can be seen in WR-D2 comparison. An underestimation of $\mathrm{Tp}$ was observed in all quantile values for both reanalysis points. This underestimation is bigger in high quantiles (around $4 \mathrm{~s}$, while for low quantiles the difference is around $2 \mathrm{~s}$ ). The overestimation of Hs quantiles and underestimation of Tp quantiles can also be observed by SS values (Table III). SS $>1$ for WR-D2 Hs comparison suggests a small overestimation of $\mathrm{Hs}$ on reanalysis data. Furthermore, the 0.83 and $0.85 \mathrm{SS}$ value $(<1)$ indicates a tendency to underestimate the Tp by the 
TABLE III

Statistical parameters obtained by $Q-Q$ comparison analysis (quantiles of the Gumbel distribution).

\begin{tabular}{ccccccccccc}
\hline & \multicolumn{4}{c}{ D1 x WR } & \multicolumn{7}{c}{ D2 $\mathbf{x}$ WR } \\
\cline { 2 - 11 } & RMSE & BIAS & SI & Pearson & SS & RMSE & BIAS & SI & Pearson & SS \\
\hline Hs & 0.02 & 0 & 0.01 & 0.99 & 0.99 & 0.1 & -0.1 & 0.03 & 0.99 & 1.03 \\
$\mathrm{Tp}$ & 2.57 & 2.53 & 0.21 & 1 & 0.83 & 2.2 & 2.17 & 0.18 & 1 & 0.85 \\
\hline
\end{tabular}
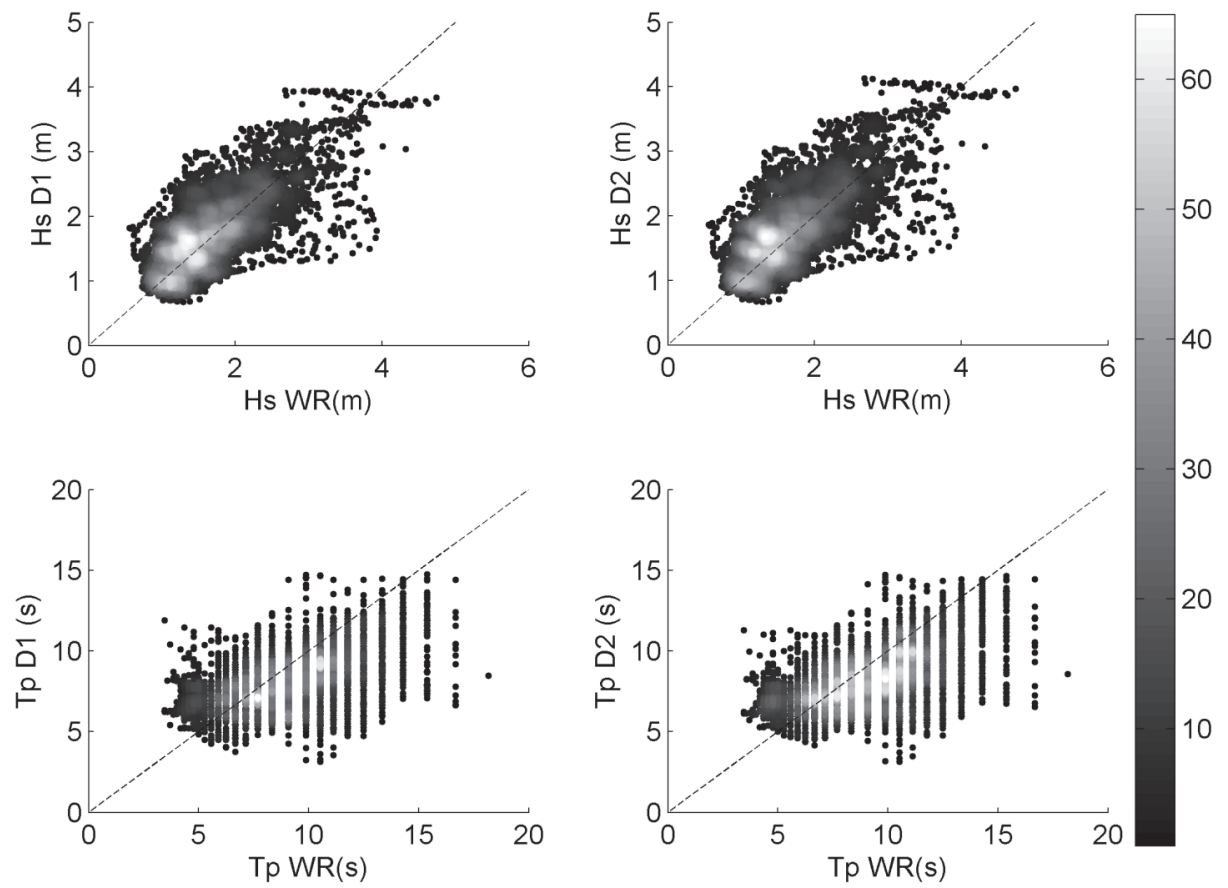

Figure 3 - Hs and Tp density dispersion between reanalysis (D1 and D2) and measured data (WR). The gray scale bar indicates the density of data that occurs in each point of the graphic.

wave model (Table III). RMS values indicate a $2 \mathrm{~cm}$ error on Hs estimation for D1 and $10 \mathrm{~cm}$ for D2. The Tp errors are greater with $2.57 \mathrm{~s}$ on D1 and $2.2 \mathrm{~s}$ on D2. SI values also indicate a small deviation from what would be the ideal.

The underestimation of $\mathrm{Tp}$, especially when considering the highest values, was also observed by D.F. Aguiar et al. (unpublished data) when comparing NWW3 (NOAA WW3) data to the buoy on the coast of Rio Grande do Sul. This underestimation of high values can be attributed to the spatial and temporal resolution of atmospheric reanalysis used as input for the wave models, not being efficient on reproducing extreme events as extra tropical cyclones, which are very common in South Atlantic Ocean (Reguero et al. 2012). This problem related to wind resolution still remains in recent reanalysis. The CFSRR is the most recent wind reanalysis with higher spatial and temporal resolution $\left(1 / 2^{\circ}\right.$ and $\left.1 \mathrm{~h}\right)$ when compared to NCEP reanalysis used to perform GOW and DOW data, even though the difficulty in representing these cyclones remains (Chawla et al. 2013). Furthermore, Melo $\mathrm{F}^{\mathrm{o}}$ et al. (2008) point out the difficulty in estimating Tp through wave modeling in areas where bimodal (or multimodal) sea state condition are significant, such as the south and southeast Brazil (Araujo et al. 2003); later Franco and Melo 

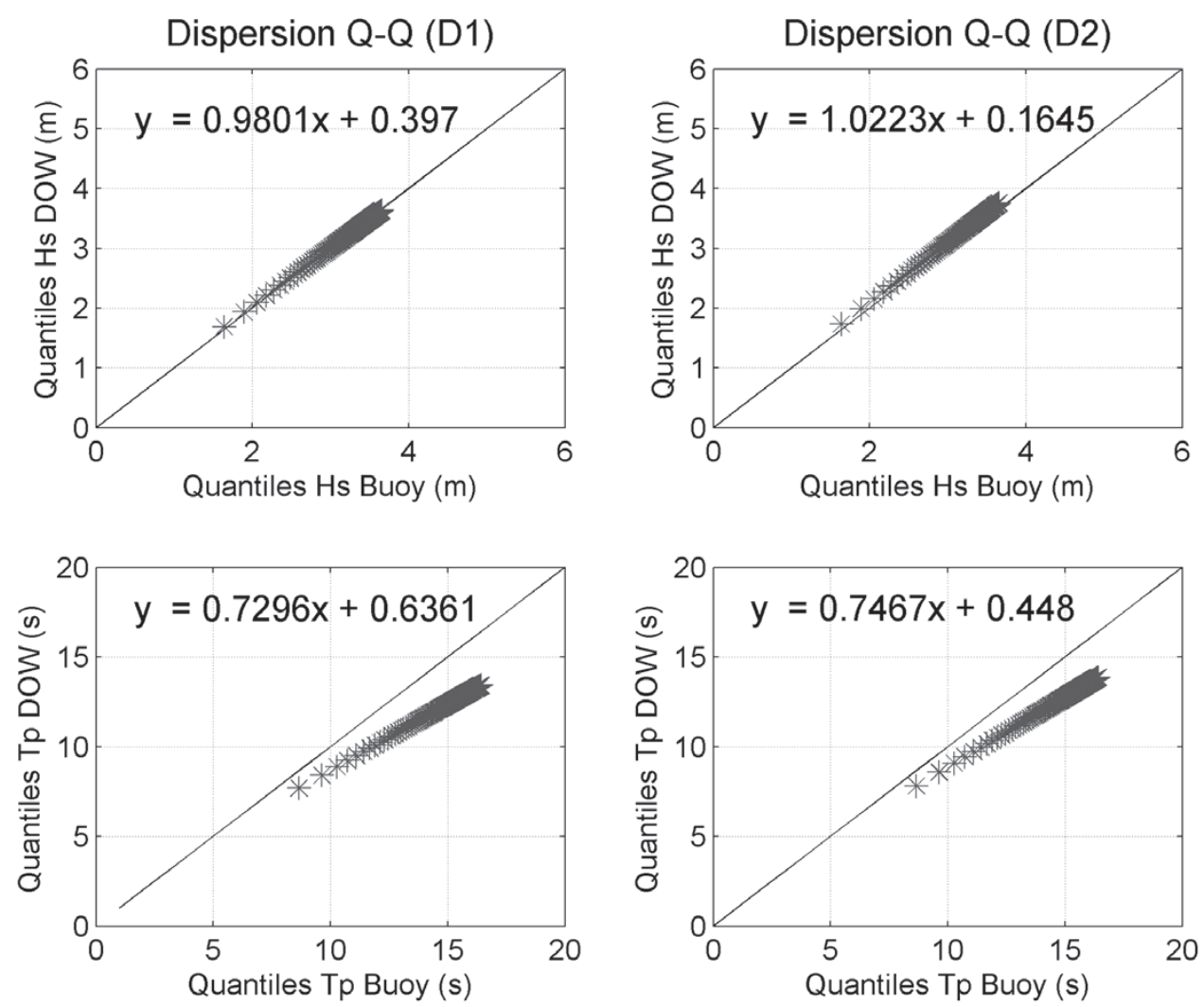

Figure 4 - Q-Q dispersion between reanalysis (D1 and D2) and buoy data (WR).

$F^{o}$ (2008) showed the importance of secondary seas in this area where over $32 \%$ of the sea states are represented by a bimodal condition. The Tp underestimation may owe to the fact that in the study area there is a high dominance of the wind seas that is not properly solved by the wave model (Espejo et al. 2014). According to Espejo et al. (2014), the results of wave climate analysis in areas dominated by mixed seas by using spectral parameters only may be misleading, because the entire spectrum is treated as one wave system. Another contribution to the underestimation of $\mathrm{Tp}$ values can be related to the source term physic package of WW3 and SWAN: Tolman-Chalikov (Tolman and Chalikov 1996). Chawla et al. (2013) mentioned that DIA parameterization (parameterization that verifies wave-wave interaction) used on this package can lead to a less intense down shifting of the spectral peak on simulations, which results in underestimation of $\mathrm{Tp}$ in storm events. However, deeper analysis of Tolman-Chalikov package is beyond the scope of this study.

Despite the differences shown here, the statistical parameters BIAS, RMS and SI showed low values for the two variables in both points. In addition, Pearson correlation values equal and very near to 1 indicate a good fit of the simulation with respect to the wave measured data. Yet, special care must be taken when using such data in extreme events analysis, where major deficiencies on the database were observed.

\section{MeAn WaVE DiRECTION}

The $\theta \mathrm{m}$ data show similar behavior (same tendency) when compared to the WR series (see Fig. 2). Nevertheless, most of the sea states ranging from $0^{\circ}$ to $90^{\circ}$ present on the measured data are not represented on DOW reanalysis. The same can be observed on 
Tp roses of the three time series (Fig. 5). Most of the wave cases from northeast are not represented on D1 and D2 roses, although winds from northeast can be observed in wind reanalysis (Fig. 5). Northeast waves shown in measured series are characteristics of the bimodal sea condition on the coast of Santa Catarina. Previous works have shown that wave climate in this area is composed by a first frequency peak representing a swell from south and a second frequency peak representing a sea from ENE to ESE (Araujo et al. 2003, Franco and Melo
$F^{o}$ 2008). The main reason for northeast waves not appearing in DOW data is related to the fact that wind seas are not properly reproduced by the wave model when using wave parameters to represent the entire spectrum as one wave system (Espejo et al. 2014), in a way that bimodal conditions generated by the influence of local winds are not considered on wave reanalysis.

Still, waves from south are not that significant in reanalysis as shown in measured data. In addition, SSW waves, which represent nearly $5 \%$ of WR
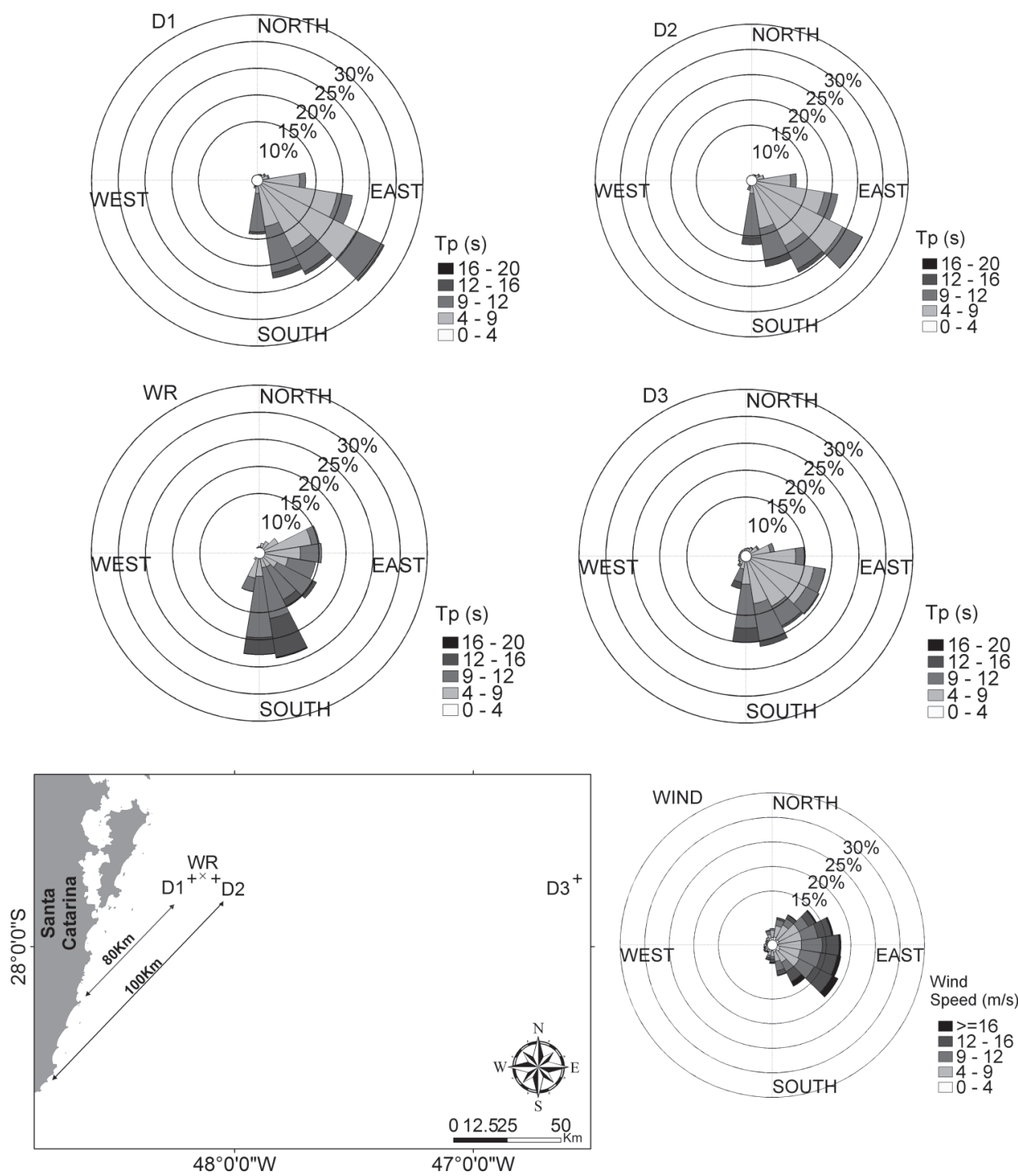

Figure 5 - Tp and wind roses of D1, D2, WR and the deeper DOW point D3. 
series, show lower occurrence on D1 and D2. The analysis of a DOW point in deeper water $(>1000 \mathrm{~m}$ deep), called D3 (Fig. 5), shows that SSW waves are well represented in deep water data and the lack of waves occurs only in shallow water (Fig. 5).

The lack of waves from SSW can be attributed to the wave growth estimation when modeling waves from the continent direction. Hasselman et al. (1973) within the JONSWAP experiment found that the peak frequency can be calculated as:

$$
f_{p}=3.5\left[\frac{g^{2} F}{U_{10}^{3}}\right]^{-0.33}
$$

where $f_{p}$ is the frequency at the spectral peak, $U_{10}$ is the wind speed at the elevation $10 \mathrm{~m}$ above the surface and $F$ is the fetch length. According to this, to generate waves with Tp equal to $9 \mathrm{~s}$ (as shown in WR) series, with winds blowing at $12 \mathrm{~m} / \mathrm{s}$ speed (Fig. 5), a $600 \mathrm{Km}$ fetch would be necessary. Nevertheless, the largest distance between D1 and D2 points and the continent is $\sim 100 \mathrm{Km}$ (Fig. 5). This suggests that there was not enough fetch for the model to generate waves from SSW.

\section{CONCLUSIONS}

Numerical wave reanalyses are a reliable option when the intention is to obtain data homogeneously sparse in time and space. DOW is a long wave reanalysis database (60 years of wave data) with high spatial and temporal resolution which is available for all $\sim 7000 \mathrm{Km}$ of the Brazilian coast through SMC Brazil database, for uses in coastal projects. A comparison between quantiles of the Gumbel distribution from DOW reanalysis database and from 11 month measured data was shown in this work. This method allow more weight to be given to the highest values of the time series, which are especially important in design projects.

After validation, the quality of data from the DOW reanalysis was verified. The database showed a good fit of the mean conditions, especially when representing Hs that was well reproduced by the wave model, although the underestimation of the $\mathrm{Tp}$ values on reanalysis data was observed. Results presented in previous works comparing reanalysis and measured data, suggest that this underestimation is related mainly to the low spatial and temporal resolution of wind data used to generate waves, not being efficient on reproducing extreme events such as extra tropical cyclones, which are very common over the South Atlantic Ocean. This problem related to wind resolution persists in recent reanalyses, even in those that present higher spatial and temporal resolution than the ones used to perform GOW and DOW data, highlighting this general modeling issue. Beside this, based on calculated statistical parameters, DOW data were considered adjusted to the values obtained by measurements.

Considering the limitations of the input data, modeling process and the size of the time series used on the validation process, such data must be cautiously used for extreme events analysis, where major deficiencies on the database were observed. Also, some care must be taken when using data from regions where bimodal wave climate are typical, because wave propagation through spectral parameters cannot properly represent these conditions.

The measured time series used in this study could provide a primary assessment of the quality of the DOW database. It is known that larger measured time series would be more adequate to verify the model performance, since eleven months' data cannot represent the entire sixty years' series. However, longer buoy time series are not available for this area and a primary analysis comparing reanalysis and measured data for this short period can be a reliable source of information for researches carried out in this coast, in which long wave time series are necessary.

\section{ACKNOWLEDGMENTS}

The authors would like to thank Felipe Mendonça Pimenta's contribution for the original manuscript; 
Andrew Cooper and Charles Finkl for reviewing terms and writing. The authors are also thankful to the Brazilian government through the Ministério do Meio Ambiente (MMA) and the Agência Brasileira de Cooperação $(\mathrm{ABC})$ for the financial support of this research (within the project Transference of Methodologies and Tools to Support the Brazilian Coastal Management). This work is part of Coastal Zone Network of INCT CLIMA.

\section{RESUMO}

Este trabalho apresenta uma validação dos parâmetros de onda da base de dados de reanálise Downscaled Ocean Waves (DOW) que compreende uma série de 60 anos de dados. Este estudo compara os quantis da distribuição de Gumbel de Hs (altura significativa de onda) e Tp (período de pico) simulado com os quantis de uma série de 11 meses de dados medidos obtidos de uma boia instalada próximo à costa de Santa Catarina. A análise através de quantis da distribuição de Gumbel permite dar mais peso aos maiores valores da distribuição que são importantes principalmente do ponto de vista de desenhos de projeto. Os parâmetros estatísticos utilizados para verificar o ajuste entre dados medidos e simulados incluíram: RMSE, BIAS, Índice de Espalhamento e Coeficiente de Correlação de Pearson. A validação da direção média $(\theta \mathrm{m})$ se deu de forma qualitativa. A base de dados apresentou bom ajuste com relação às condições médias, principalmente com relação a Hs que foi bem representada pelo modelo de ondas. A subestimação de $\mathrm{Tp}$, relacionada principalmente à baixa resolução dos dados de vento utilizados na geração de ondas, ressalta este problema comum à modelagem do clima de ondas. Com base nos parâmetros estatísticos calculados, os dados da base DOW foram considerados comparáveis aos valores medidos; no entanto, deve-se ter cuidado ao utilizar tais dados na análise de eventos extremos e em locais com condições de mares bimodais, onde maiores deficiências da base de dados foram observadas.

Palavras-chave: DOW, validação, reanálise de ondas, WAVEWATCHIII.

\section{REFERENCES}

Araujo Ces, Franco D, Melo Fo E and Pimenta F. 2003. Wave regime characteristics of the Southern Brazilian coast. In: International Conference on Coastal and Port Engineering in Developing Countries, Colombo, Siri Lanka. Proceedings...COPEDEC VI 97: 1-15.

ARINAGA RA AND CHEUNG KF. 2012. Atlas of a global wave energy from 10 years of reanalysis and hindcast data. Renew Energy 39: 49-64.

BATTJES JA. 1972. Long-term wave height distributions at seven stations around the British Isles. Dtsch Hydrogr Z 25(4): 179-189.

Booij N, Holthuijsen LH AND Ris RC. 1999. A thirdgeneration wave model for coastal regions. Model description and validation. J Geophys Res 104(C4): 76497666.

BROWN JM. 2010. A case study of combined wave and water levels under storm conditions using WAM and SWAM in a shallow water application. Ocean Model 35: 215-229.

CAIRES S AND STERL A. 2005a. A 100-year return value estimates for ocean wind speed and significant wave height from the ERA-40 data. J Climate 18: 1032-1048.

CAIRES S AND STERL A. 2005b. A new nonparametric method to correct model data: Application to significant wave height from the ERA-40 Re-analysis. J Atmos Ocean Tech 22: 443-459.

CAmus P, Méndez FJ, Medina R, Tomas A And Izaguirre C. 2013. High resolution downscaled ocean waves (DOW) reanalysis in coastal areas. Coast Eng 72: 56-68.

Chawla A, SPINDLER DM AND TOLMAN HL. 2013. Validation of a thirty year wave hindcast using Climate Forecast Reanalysis winds. Ocean Model 70: 189-206.

EsPejo A, CAmus P, Losada I AND Mendez F. 2014. Spectral ocean wave climate variability based on atmospheric circulation patterns. J Phys Oceanogr 44(8): 2139-2152.

Franco D AND MElo Fo E. 2008. Relevância dos mares secundários na caracterização do regime de ondas ao largo da Ilha de Santa Catarina, SC (2002 - 2005). In: Seminário e Workshop em Engenharia Oceânica. Rio Grande, Brasil. Proceedings...SEMENGO III. Available in: http://www. semengo.furg.br/index.php/historico

HASSELMAN K ET AL. 1973. Measurements of wind-wave growth and swell decay during the Joint North Sea Wave Project (JONSWAP). Dtsch Hydrogr Z 8(12): 1-95.

HASSELMAN S ETAL. 1988. The WAM model: a third generation ocean wave prediction model. J Phys Oceanogr 18(12): 1775-1810.

Heras MM, Burgers G AND JANSSEN PAEM. 1995. Wave data assimilation in the WAM wave model. J Marine Syst 6: 77-85.

JANSSEN PAEM, HANSEN B AND BIDLOT JR. 1997. Verification of the ECMWF wave forecasting system against buoy and altimeter data. Wea Forecasting 12(4): 763-784.

KISTLER R ET AL. 2001. The NCEP-NCAR 50-year reanalysis: Monthly means CD-ROM and documentation. B Am Meteorol Soc 82(2): 247-268. 
Melo $\mathrm{F}^{\mathrm{o}}$ E, Hammes GR and Franco D. 2006. Estudo de caso: A ressaca de agosto de 2005 em Santa Catarina. In: Seminário e Workshop em Engenharia Oceânica, Rio Grande, Brasil. Proceedings...SEMENGO II. Available in: http://www.semengo.furg.br/index.php/historico

Melo Fº E, Hammes GR, Franco D AND Romes M. 2008. Avaliação de desempenho do modelo WW3 em Santa Catarina. In: Seminário e Workshop em Engenharia Oceânica, Rio Grande, Brasil. Proceedings...SEMENGO III. Available in: http://www.semengo.furg.br/index.php/ historico

Melo $F^{\circ}$ E, Romeu MA AND Hammes GR. 2010. Condições extremas de agitação marítima ao largo de Rio Grande a partir do modelo WW3. In: Seminário e Workshop em Engenharia Oceânica, Rio Grande, Brasil. Proceedings... SEMENGO IV. Available in: http://www.semengo.furg. br/index.php/historico

Mínguez R, Espejo A, Tomás A, MÉndez FJ AND LosAdA IJ. 2011. Directional calibration of wave reanalysis data bases using instrumental data. J Atmos Ocean Tech 28: 1466-1485.

Mostafa Siadatmousavi S, Jose F And Stone GW. 2011 Evaluation of two WAN white capping parametrization using parallel unstructured SWAN with application to the northern Gulf of Mexico, USA. Appl Ocean Res 33(1): 23-30.

RASCLE N AND ARDHUIN F. 2013. A global wave parameter database for geophysical applications.Part 2: Model validation with improved source term parametrization. Ocean Model 70: 174-188.
Reguero BG, Menéndez M, Méndez R, Mínguez R And LOSADA IJ. 2012. A Global Ocean Wave (GOW) calibrated reanalysis from 1948 onwards. Coast Eng 65: 38-55.

SAHA S ET AL. 2010. The NCEP climate forecast system reanalysis. B Am Meteorol Soc 91: 1015-1057.

STERL A AND CAIRES S. 2005. Climatology, variability and extrema of ocean waves: the web-based KNMI-ERA-40 wave ATLAS. Int J Climatol 25: 963-977.

TOLMAN HL. 1991. A third-generation model for wind wave on slowly varying unsteady and inhomogeneous depths and currents. J Phys Oceanogr 21: 782-797.

TOLMAN HL, BALASUBRAMANIYAN B, BURROUGHS LD, Chalikov DV, CHAO YY, CHEN HS AND GERALD VM. 2002. Development and implementation of windgenerated ocean surface wave models at NCEP. B Am Meteorol Soc 17: 311-333.

TOLMAN HL AND CHALIKOV D. 1996. Source terms in a thirdgeneration wind wave model. J Phys Oceanogr 26: $2497-$ 2517.

UpPala SM ET AL. 2005. The ERA-40 reanalysis. Q J Roy Meteor Soc 131: 2961-3012.

YOUNG IR. 1999. Wind Generated Ocean Waves. $1^{\text {st }}$. ed., Oxford: Elsevier, $307 \mathrm{p}$. 